\title{
Understanding Charge Transport in Endohedral Fullerene Single- Crystal Field-Effect Transistors
}

Xiaoming Zhao, ${ }^{1 \dagger}$ Tianjun Liu, ${ }^{2 \dagger}$ Wenda Shi, ${ }^{1}$ Xueyan Hou, ${ }^{1}$ Zilu Liu, ${ }^{3}$ T. John S. Dennis $^{1 *}$

${ }^{1}$ School of Physics and Astronomy, Queen Mary University of London, Mile End Road, London E1 4NS, United Kingdom

${ }^{2}$ School of Engineering and Materials Science, Queen Mary University of London, Mile End Road, London E1 4NS, United Kingdom.

${ }^{3}$ School of Biological and Chemical Sciences, Queen Mary University of London, Mile End Road, London E1 4NS, United Kingdom

$\dagger \mathrm{X}$. Zhao and T. Liu have the equivalent contribution

Abstract: The encapsulation of nitrogen within $\mathrm{C}_{60}$ forms non-metallic endohedral fullerene $\mathrm{N} @ \mathrm{C}_{60}$. Previous calculations show that the encapsulated nitrogen may favor more efficient charge injection and transport under external electric fields when compared to $\mathrm{C}_{60}$, suggesting that $\mathrm{N} @ \mathrm{C}_{60}$ may be a promising candidate for application in organic electronic devices. However, owing to difficulties in both synthesis and purification, the potential application of $\mathrm{N} @ \mathrm{C}_{60}$ under external electric field has not been previously studied experimentally and its intrinsic charge transport mechanism remains unknown, which hinders more widely applications of endohedral fullerene in organic electronic devices. Here, we demonstrate the field-effect study and photo-detective applications of solution-grown $\mathrm{N} @ \mathrm{C}_{60}$ single crystals. Organic fieldeffect transistors (OFETs) based on them exhibit electron mobilities up to $2.23 \mathrm{~cm}^{2} \mathrm{~V}^{-}$ 
${ }^{1} \mathrm{~s}^{-1}$. Furthermore, the electrical properties show a favorable band-like charge transport mechanism from $180 \mathrm{~K}$ to $300 \mathrm{~K}$, and photodetectors based on them yield a highly sensitive photo-conductive property under the near-infrared (NIR) illumination with a responsivity of $177.3 \mathrm{~A} \mathrm{~W}^{-1}$. This study, which outlined the intrinsic charge transport properties of $\mathrm{N} @ \mathrm{C}_{60}$, should not only enable significant advancements for the highmobility n-type OFETs and highly sensitive photosensing applications, but also provide a reference for studying fundamental physics of endohedral fullerene.

\section{Introduction}

Organic field-effect transistors (OFETs) have attracted continuous research attention for flexible and light-weight electronic devices, such as circuits, ${ }^{1-4}$ displays, ${ }^{5}$ sensors, ${ }^{6-10}$ and photodetectors. ${ }^{1-14}$ Among them, photodetectors, which translate optical signal into electrical signal, playing a vital role in high-resolution imaging, lightwave communications, and optical interconnection systems. ${ }^{15-20}$ Organic single crystals, being free of grain boundaries and molecular disorders, are regards as promising charge transport media for organic electronic devices. ${ }^{21,22}$ Fullerene $\mathrm{C}_{60}$, is a superstar organic semiconductor for organic single crystal electronics, as it has achieved the highest electron mobility among organic semiconductors ${ }^{23}$ and the photodetectors based on it exhibit highly sensitive photo-responsivity. ${ }^{14,24}$

In recent years, endohedral fullerenes have attracted broad attentions due to their unique forms and new properties that are unexpected for empty fullerenes. ${ }^{25}$ Endohedral fullerenes can be classified into endohedral metallofullerenes and nonmetallo fullerenes according to different atoms enclosed. ${ }^{26}$ Endohedral metallofullerene 
OFETs have been fabricated with Dy@C $82, \mathrm{La}_{2} @ \mathrm{C}_{80}$ and so forth. ${ }^{27,28}$ However, owing to difficulties in the formation of crystals of endohedral metallofullerenes, they have only be applied in OFETs as amorphous films and the electron mobility $(\mu)$ values of these OFETs present only around $10^{-4} \mathrm{~cm}^{2} \mathrm{~V}^{-1} \mathrm{~s}^{-1} \cdot{ }^{27,28}$ The encapsulation of nitrogen within $\mathrm{C}_{60}$ forms non-metallic endohedral fullerene $\mathrm{N} @ \mathrm{C}_{60}$. It is stable because the location of the atomic nitrogen is in the center of the $\mathrm{C}_{60}$ cage and it is well protected from the ambient environment..$^{29,30}$ This property enables $\mathrm{N} @ \mathrm{C}_{60}$ to form single crystals as easily as $\mathrm{C}_{60}$. Previous calculations show that the encapsulated nitrogen decreases the lowest unoccupied molecular orbital (LUMO) energy level of $\mathrm{C}_{60}$, which may favor more efficient charge injection and transport under external electric fields when compared to $\mathrm{C}_{60}{ }^{31,32}$ This ease of crystal formation, when coupled to efficient electron transport properties suggests that $\mathrm{N} @ \mathrm{C}_{60}$ may be a promising candidate for FET applications. Unfortunately, owing to difficulties in both synthesis and purification, the potential application of $\mathrm{N} @ \mathrm{C}_{60}$ under external electric field has not been previously studied experimentally.

Herein, we report the first demonstration of $\mathrm{N} @ \mathrm{C}_{60}$ single crystal OFETs and highly sensitive NIR photodetectors. These are based on solution-grown onedimensional single crystals of $\mathrm{N} @ \mathrm{C}_{60}$. The morphologies and crystal structures are studied by atomic force microscope (AFM), scanning electron microscope (SEM) and selected area electron diffraction (SAED) along with high-resolution transmission electron microscope (TEM). OFETs based on $\mathrm{N} @ \mathrm{C}_{60}$ single crystals present $\mu$ as high as $2.23 \mathrm{~cm}^{2} \mathrm{~V}^{-1} \mathrm{~s}^{-1}$. A temperature dependence study shows a band-like electron 
mobility mechanism, which is the signature of high-quality crystals and excellent electrical conduction. Photodetectors based on $\mathrm{N} @ \mathrm{C}_{60}$ single crystals present highly sensitive photoconductivity properties with a high responsivity of $177.3 \mathrm{~A} \mathrm{~W}^{-1}$ under NIR illumination, which is among the highest for the reported organic photodetectors working under similar conditions. The high mobility and highly sensitive photoresponsivity of the $\mathrm{N} @ \mathrm{C}_{60}$ single crystals will accelerate the development of the highperformance OFETs and next-generation photodetection devices.

\section{Results and Discussions}

$\mathrm{N} @ \mathrm{C}_{60}$ was produced by nitrogen-ion implantation of $\mathrm{C}_{60}$ films and was purified by a two-step high-performance liquid chromatography (HPLC) process as reported in detail by us previously. ${ }^{33}$ The droplet-pinned crystallization (DPC) is reported to be a simple and efficient method to align large-scale $\mathrm{C}_{60}$ single crystals. ${ }^{23}$ The DPC method allows the crystals to grow along a substrate surface, with close contact between the single crystals and the substrates. Thus, it favors the formation of OFET charge transporting channels. ${ }^{34-36}$ Using this method, self-aligned one-dimensional N@C 60 crystals were successfully prepared (Figure 1a).

After the preparation of single crystals, the crystal morphologies and crystal structures were studied. To reduce dielectric surface traps, these were grown on octadecylsilanes (OTS) modified $\mathrm{SiO}_{2} / \mathrm{Si}$ substrates, rather than bare $\mathrm{SiO}_{2} / \mathrm{Si}$ substrates. ${ }^{37-40}$ The average dimensions were obtained based on 50 single crystals. Optical microscope $(\mathrm{OM})$ shows that the obtained $\mathrm{N} @ \mathrm{C}_{60}$ needle crystals had an average length of $294 \mu \mathrm{m}$ with a standard deviation of $54 \mu \mathrm{m}$, i.e., $(294 \pm 54 \mu \mathrm{m})$, which 
is compared to that of reported $\mathrm{C}_{60}$ needle crystals. ${ }^{23}$ The SEM images, an example of which is shown in Figure 1b, indicates that the average width of $\mathrm{N} @ \mathrm{C}_{60}$ crystal is (465 $\pm 64) \mathrm{nm}$ while AFM image shows a faceted shape and very smooth surfaces with average thickness of $(285 \pm 47) \mathrm{nm}$ for $\mathrm{N} @ \mathrm{C}_{60}$ needle crystal (Figure 1c), indicative of crystalline structures. To gain more insight into the crystal structures of the $\mathrm{N} @ \mathrm{C}_{60}$, the samples were characterized by transmission electron microscopy (TEM) and the selected area electron diffraction (SAED), as shown in Figure 1d. The SAED diffraction spot pattern is very similar to the reported crystal structure of solutiongrrown $\mathrm{C}_{60} \cdot m$-xylene single crystals in the literature. ${ }^{23}$ The SAED patterns from different areas of one single crystal are all identical, indicating the single-crystalline nature of as-prepared crystals. To further confirm the crystal structure, we performed an X-ray diffraction (XRD) study. The room-temperature XRD pattern of the asprepared single crystals is shown in Figure S1. The structure is indexed to be a hexagonal system and cell dimensions are $a=23.11 \AA, b=23.11 \AA$ and $c=10.10 \AA$. This is similar to the reported $\mathrm{C}_{60}$ nanorods achieving by slow solvent evaporation of an $m$-xylene solution of $\mathrm{C}_{60}(a=23.76 \AA, b=23.76 \AA$ and $c=10.08 \AA) .{ }^{41}$ Further information about the crystallinity was obtained from a high-resolution transmission electron microscopy (HRTEM) study (Figure S2.). Not only does this image confirm that the $\mathrm{N} @ \mathrm{C}_{60}$ needles are single crystals, it also shows that the measured $1.16 \mathrm{~nm}$ spacing between neighbouring lattice planes equals to the distance between two (110) crystal planes obtained by XRD. Therefore, (001) is the preferential growth direction 
of as-prepared $\mathrm{N} @ \mathrm{C}_{60}$ crystals. These morphology studies indicate that high quality $\mathrm{N} @ \mathrm{C}_{60}$ single crystals are successfully obtained.

OFETs were fabricated based on as-grown single crystal needles in a top-contact bottom-gate device configuration (Figure 2a). The devices were tested under vacuum, and the saturation region electron mobility was obtained. The channel length and width were obtained based on SEM images as shown in Figure 2b. The transfer and output characteristics of typical n-channel OFETs were obtained (Figure 2c and 2d), exhibiting good gate modulation. The mobility was gate bias-dependent (Figure S3), and the mobility was extracted following the method reported in the literature. ${ }^{42}$ At a $\mathrm{N} @ \mathrm{C}_{60}$ concentration of $0.5 \mathrm{mg} \mathrm{mL}^{-1}$, the highest electron mobility $(\mu)$ of $2.23 \mathrm{~cm}^{2} \mathrm{~V}^{-}$ ${ }^{1} \mathrm{~s}^{-1}$, on/off current ratio $>10^{4}$, and threshold voltage $\left(V_{\mathrm{T}}\right)$ of $19.52 \mathrm{~V}$ were achieved (Figure 2c). As the measurement of contact channel width can strongly influence the measurement of charge carrier mobility, we therefore measured the channel length of 100 devices and summarized the relevant mobilities in Figure S4. Based on these 100 devices, the average $\mu$ is $(1.84 \pm 0.26) \mathrm{cm}^{2} \mathrm{~V}^{-1} \mathrm{~s}^{-1}$. To the best of our knowledge, the mobility of our $\mathrm{N} @ \mathrm{C}_{60}$-based OFETs is the highest for OFETs based on endohedral fullerenes. $^{27,28}$

OFETs based on $\mathrm{N} @ \mathrm{C}_{60}$ single crystals grown from solutions of varied $\mathrm{N} @ \mathrm{C}_{60}$ concentrations were then examined. Different concentrations of $\mathrm{N} @ \mathrm{C}_{60}$ in $m$-xylene were used for crystal growth to uncover the preparation condition-mobility relationships. The maximum solubility of $\mathrm{N} @ \mathrm{C}_{60}$ in $m$-xylene is around $2 \mathrm{mg} \mathrm{mL}^{-1}$, five concentrations $0.1,0.5,1,1.5$ and $2 \mathrm{mg} \mathrm{mL}^{-1}$ were used for crystal growth, 
respectively. As the concentration of $\mathrm{N} @ \mathrm{C}_{60}$ increased from 0.5 to $2.0 \mathrm{mg} \mathrm{mL}^{-1}$, the mobility decreased (Figure 2e), while the channel coverage continued to increase. This result has also been observed for $\mathrm{C}_{60}$ OFETs. ${ }^{34}$ The reason for it is that the morphology of the crystals grown at high concentration is thick disordered and multi-stacked, whereas low concentrations give well-aligned crystals. In addition, crystals grown at low concentration show lower thickness. This gives a low contact resistance, which is beneficial for charge injection.

To study the charge transport mechanism of $\mathrm{N} @ \mathrm{C}_{60}$ single crystals, OFETs based on as-prown crystals were tested in vacuum when cooled from 300 to $80 \mathrm{~K}$. As shown in Figure 3a-c, the $\mu$ of the $\mathrm{N} @ \mathrm{C}_{60}$ single-crystal OFETs presents two different behaviors in different temperature regions. The transition temperature $\left(T^{*}\right)$ between the two different regions is $180 \mathrm{~K}$, and a highest $\mu$ of $2.91 \mathrm{~cm}^{2} \mathrm{~V}^{-1} \mathrm{~s}^{-1}$, is also obtained at this temperature. Figure 3a shows the transfer curves of OFETs at the temperature from $80 \mathrm{~K}$ to $180 \mathrm{~K}$. In the low-temperature region $(80 \mathrm{~K}-180 \mathrm{~K})$, the $\mu$ increased while heating the devices, producing a positive mobility-temperature coefficient (Figure 3c). The mobility increases from $2.04 \mathrm{~cm}^{2} \mathrm{~V}^{-1} \mathrm{~s}^{-1}$ at $80 \mathrm{~K}$ to $2.91 \mathrm{~cm}^{2} \mathrm{~V}^{-1} \mathrm{~s}^{-1}$ at $180 \mathrm{~K}$. Such behavior is commonly observed in organic field effect transistors, ${ }^{21,43-45}$ reflecting the gate voltage filling up low-mobility trap states. ${ }^{46}$ This indicates that the charge transport through $\mathrm{N} @ \mathrm{C}_{60}$ single crystals follows a thermally activated mechanism at these temperatures. ${ }^{46}$ In this temperature region, most of the charge carriers are trapped in localized shallow traps which are formed by chemical impurities, structural disorders, and surface states. ${ }^{42-44}$ Charge transport occurs via the extended states (transport level) 
when the carriers are thermally activated and released from the traps. ${ }^{42-44}$ Fitting the data with the equation (1),

$$
\mu=\mu_{0} \exp \left(\frac{-E_{a}}{k_{B} T}\right)
$$

where $E_{\mathrm{a}}$ is the activation energy and $k_{\mathrm{B}}$ is the Boltzmann constant, we obtained an activation energy of $6.34 \mathrm{meV}$, as shown in Figure 3d. The activation energy of $\mathrm{N} @ \mathrm{C}_{60}$ single crystal here $(6.34 \mathrm{meV})$ is comparable to the reported values for highperformance organic semiconductors, such as TIPS-PEN $\left(E_{\mathrm{a}}=5.7 \mathrm{meV}\right){ }^{44}$ and TIPSTAP $\left(E_{\mathrm{a}}=5.6 \mathrm{meV}\right) .{ }^{47}$ This implies that a low degree of disorders presented in $\mathrm{N} @ \mathrm{C}_{60}$ single crystals and at the interface between the single crystals and the substrates. ${ }^{46-48}$

In the high-temperature region $(180 \mathrm{~K}-300 \mathrm{~K}), \mu$ exhibits a negative mobilitytemperature coefficient. The field effect mobilities of $\mathrm{N} @ \mathrm{C}_{60}$ OFETs decrease monotonically from 2.91 to $2.23 \mathrm{~cm}^{2} \mathrm{~V}^{-1} \mathrm{~s}^{-1}$ by heating from $180 \mathrm{~K}$ to $300 \mathrm{~K}$. The negative mobility-temperature coefficient is generally observed for band-like charge transport mechanism, in which charge carriers delocalize over a few molecules. ${ }^{44,45}$ With temperature increasing, thermal energy becomes sufficient and the influence of trapping could be eliminated. In this temperature region, the overall charge transport was dominated by the intrinsic charge transport through the delocalized state within the $\mathrm{N} @ \mathrm{C}_{60}$ single crystals. ${ }^{44,45}$ Band-like temperature dependence is the signature of high-quality crystals and excellent electrical conduction. ${ }^{48}$

To study the applications of $\mathrm{N} @ \mathrm{C}_{60}$ single crystals in photodetectors, we carried out photodetection measurements on $\mathrm{N} @ \mathrm{C}_{60}$ OFETs. In our photoconduction measurement, NIR light irradiation was provided by NIR laser diodes $(780 \mathrm{~nm})$. As 
depicted in Figure $\mathbf{4 a}$ and $\mathbf{4 b}$, with NIR irradiation on and off, the photocurrent of a N@C 60 OFET shows two different states. Without NIR illumination, the current was $2 \mathrm{nA}$ at an applied bias of $30 \mathrm{~V}$. However, under a $9.5 \mathrm{~mW} \mathrm{~cm} \mathrm{~cm}^{-2} \mathrm{NIR}$ illumination, the photocurrent was as $164 \mathrm{nA}$, leading to an on/off ratio of 82. According to the timeresolved photo-response measurements (Figure 4c), the switch between on and off states is very sentivite with response time around $180 \mathrm{~ms}$ and this process is completely reversible. These excellent features enable the as-fabricated devices to act as highperformance photosensitive switches. Photoresponsivity $(R)$ is a key factor to identify the light-sensitive performance of photodetectors. To further evaluate the photoresponse, we calculated photo-responsivity of $\mathrm{N} @ \mathrm{C}_{60}$ OFET by the equation (2):

$$
R=\frac{I_{\text {light }}-I_{\text {dark }}}{P S}
$$

Where $I_{\text {light }}$ is the photocurrent when exposed to NIR light, $I_{\text {dark }}$ is the is the dark current without illunination, $P$ is the incident power density and $S$ is the active area. In these devices, the active area is measured to be $\sim 9.13 \mu \mathrm{m}^{2}$. The specific detectivity $\left(D^{*}\right)$ can be calculated by the equation (3):

$$
D^{*}=\frac{R S^{1 / 2}}{\left(2 q I_{\text {dark }}\right)^{1 / 2}}
$$

where $q$ is the electron charge. We plotted the device $R$ and $D^{*}$ as functions of the applied bias in Figure 4d. The maximum responsivity of $177.3 \mathrm{~A} \cdot \mathrm{W}^{-1}$ was obtained at $V_{\mathrm{GS}}=30 \mathrm{~V}$ and $P=9.5 \mathrm{~mW} \mathrm{~cm} \mathrm{~cm}^{-2}$. The maximum $D^{*}$ of $7.5 \times 10^{9}$ Jones was also obtained at the same condition. However, both $R$ and $D^{*}$ decreases by increasing $V_{\mathrm{GS}}$ beyond $30 \mathrm{~V}$ due to the reduced photocurrent. Both $R$ and $D^{*}$ exhibit gate-modulated 
property; The applied bias can effectively control the on and off states of the devices. This feature provides $\mathrm{N} @ \mathrm{C}_{60}$ based photo-detectors with great potential in video frame rate imaging applications. ${ }^{49}$ These promising results present an excellent performance of our $\mathrm{N} @ \mathrm{C}_{60}$ single-crystal photodetectors in the near-infrared region, which are more satisfactory values compared with those of other reported photodetectors working under similar conditions (Table 1). ${ }^{13,14,50-54}$ The high photoresponse performance demonstrates that $\mathrm{N} @ \mathrm{C}_{60}$ single crystals can serve as excellent NIR photodetection and photosensing materials.

\section{Conclusions}

In conclusion, the first demonstration of endohedral fullerene single crystals applied in OFETs and highly sensitive NIR photodetectors was reported. The maximum electron mobility of OFETs based on self-aligned N@ $\mathrm{C}_{60}$ single crystals is $2.23 \mathrm{~cm}^{2} \mathrm{~V}^{-}$

${ }^{1} \mathrm{~s}^{-1}$. Photodetectors based on as-grown single crystals present highly sensitive photoconductivity properties with a responsivity of $177.3 \mathrm{~A} \mathrm{~W}^{-1}$ in the near-infrared (NIR) region, which is a more satisfactory value compared with those of other reported OFETs working under similar conditions. The high mobility and highly sensitive photoresponsivity of the $\mathrm{N} @ \mathrm{C}_{60}$ single crystals pave a new way for the significant advancements in OFETs and photodetection applications.

\section{Experimental Section}

Materials: $\mathrm{C}_{60}$ with purity of $99.95 \%$ was purchased from SES research, nOctadecyltrimethoxysilane (OTS) was purchased from Sigma Aldrich. m-xylene, 
toluene and other solvents were purchased from Sigma Aldrich. All materials were used without further purification. $\mathrm{N} @ \mathrm{C}_{60}$ was synthesized and purified following our previous report. ${ }^{33}$

Wafer modification: Highly doped silicon wafer with $300 \mathrm{~nm} \mathrm{SiO} 2$ layer were modified by OTS monolayer following previous report. ${ }^{37}$

Crystallization: Crystals were grown in situ on substrates following the method in the literature. $^{22}$ The concentration of $\mathrm{N} @ \mathrm{C}_{60}$ in $m$-xylene is from $0.1-2.0 \mathrm{mg} \mathrm{mL} \mathrm{m}^{-1}$. Morphology Characterization: OM images were recorded using an Olympus BX 60 optical microscope. AFM images were recorded in a NT-MDT Ntegra atomic force microscope in semi-contact mode. SEM images were recorded by an FEI Inspect-F scanning electron microscope. XRD pattern was obtained by a Rigaku D/max-2500 Xray diffractometer using filtered $\mathrm{Cu} \operatorname{Ko}$ radiation $(\lambda=1.54 \AA)$ and the $2 \theta$ is ranging from $5^{\circ}$ to $40^{\circ}$. The XRD pattern was firstly compared to the reported XRD pattern of $\mathrm{C}_{60}$ nanorod $(a=b=23.76 \AA, c=10.08 \AA)$ in the literature. ${ }^{41}$ We then calculated the cell dimensons according to Bragg's Law. TEM images were recorded in a JEOL JEM2010 transmission electron microscope in a high-resolution mode and electron diffraction configuration, at an accelerating voltage of $200 \mathrm{kV}$. The single crystals were grown on the carbon coated mica substrates by the method mentioned above. Then carbon film were put onto the water surface and then copper grids were employed to pick up the single crystals. The samples were annealled under vacuum for 24 hours and then go for TEM observation. 
Device fabrication and measurement: OFETs were fabricated in a top-contact bottomgate device configuration by depositing $50 \mathrm{~nm} \mathrm{Au}$ as source and drain electrodes. Current-voltage characteristics of the devices were carried out under a vacuum of $10^{-6}$ Torr on a Lake Shore model PS-100 tabletop cryogenic probe station with a Keithley 4200-SCS semiconductor characterization system. The field-effect mobility was calculated in the saturation regime according to the equation $I_{\mathrm{DS}}=\left(\mu W C_{i} / 2 L\right)\left(V_{\mathrm{G}}-\right.$ $\left.V_{\mathrm{T}}\right)^{2}$, where $I_{D S}$ is the drain-source current, $\mu$ is the field-effect mobility, $W$ is the channel width, $L$ is the channel length, $C_{\mathrm{i}}$ is the capacitance per unit area of the gate dielectric layer, $V_{\mathrm{G}}$ is the gate voltage and $V_{\mathrm{T}}$ is the threshold voltage. The channel length $(L)$ is $25 \mathrm{~mm}$ and the channel width $(W)$ was obtained from the SEM images.

Temperature-dependent measurement: The current-voltage measurement was carried out on the same Lake Shore model PS-100 tabletop cryogenic probe tation at a background pressure of $1 \times 10^{-6}$ torr. The cooling process from $300 \mathrm{~K}$ to $80 \mathrm{~K}$ was realized by introducing liquid nitrogen into the insulation cabin outside the sample cabin. Temperature of the samples was balanced by simultaneous heat under the sample holder.

Photoresponse Measurement: Photoresponse measurements were performed on the same Lake Shore model PS-100 tabletop cryogenic probe tation by two-terminal mode. The devices were put in a sample chamber under a vacuum of $10^{-6}$ Torr at room temperature. The parameters were analysed using a Keithley 4200-SCS semiconductor characterization system. 


\section{Supporting Information.}

XRD pattern of as-prepared $\mathrm{N} @ \mathrm{C}_{60}$ single crystals. HRTEM image of as-prepared

$\mathrm{N} @ \mathrm{C}_{60}$ single crystal. Typical gate-bias dependent mobility for devices based on $\mathrm{N} @ \mathrm{C}_{60}$ needle crystals. Channel width dependences of mobilities in OFETs based on N@C60 single crystals. 


\section{AUTHOR INFORMATION}

\section{Corresponding Author}

*Email: T. J. S. Dennis: j.dennis@,qmul.ac.uk

\section{Author Contributions}

X.Z. and T.L. conceived the idea and design of the experiments. X.Z. and T.J.S.D performed the synthesis and purification of $\mathrm{N} @ \mathrm{C}_{60}$. X.Z. and T.L. performed the single crystal growth of $\mathrm{N} @ \mathrm{C}_{60}$. X.Z. and X.H. carried out the image collection and result analysis of OM. X.Z. and W.S. carried out the image collection and result analysis of SEM. X.Z. and Z.L. carried out the image collection and result analysis of AFM. X.Z. and T.L. performed the measurements and result analysis of TEM and SAED. X.Z. and T.L. fabricated the OFET devices and performed the temperature-dependent measurements and data analysis. X.Z and W.S. carried out the photo-response studies. X.Z. wrote the manuscript and all authors contributed to the revision of the manuscript. T.J.S.D. supervised this work.

†.Z. and T.L. authors contributed equally.

\section{Notes}

The authors declare no competing financial interest.

\section{ACKNOWLEDGMENT}

X. Zhao, T. Liu, W. Shi, X. Hou and Z. Liu each thank the China Scholarship Council for funding. 


\section{References}

(1) Sekitani, T.; Zschieschang, U.; Klauk, H.; Someya, T. Flexible Organic Transistors and Circuits with Extreme Bending Stability. Nat. Mater. 2010, 12, $1015-1022$.

(2) Minder, N. A.; Lu, S.; Fratini, S.; Ciuchi, S.; Facchetti, A.; Morpurgo, A. F. Tailoring the Molecular Structure to Suppress Extrinsic Disorder in Organic Transistors. Adv. Mater. 2014, 8, 1254-1260.

(3) Klauk, H.; Zschieschang, U.; Pflaum, J.; Halik, M. Ultralow-Power Organic Complementary Circuits. Nature 2007, 7129, 745-748.

(4) Crone, B.; Dodabalapur, A.; Lin, Y.-Y.; Filas, R. W.; Bao, Z.; LaDuca, A.; Sarpeshkar, R.; Katz, H. E.; Li, W. Large-Scale Complementary Integrated Circuits Based on Organic Transistors. Nature 2000, 6769, 521-523.

(5) Gelinck, G. H.; Huitema, H. E. A.; van Veenendaal, E.; Cantatore, E.; Schrijnemakers, L.; van der Putten, J. B. P. H.; Geuns, T. C. T.; Beenhakkers, M.; Giesbers, J. B.; Huisman, B.-H. Flexible Active-Matrix Displays and Shift Registers Based on Solution-Processed Organic Transistors. Nat. Mater. 2004, 2, 106-110.

(6) Mannsfeld, S. C. B.; Tee, B. C. K.; Stoltenberg, R. M.; Chen, C. V. H. H.; Barman, S.; Muir, B. V. O.; Sokolov, A. N.; Reese, C.; Bao, Z. Highly Sensitive Flexible Pressure Sensors with Microstructured Rubber Dielectric Layers. Nat. Mater. 2010, 10, 859-864. 
(7) Sekitani, T.; Yokota, T.; Zschieschang, U.; Klauk, H.; Bauer, S.; Takeuchi, K.; Takamiya, M.; Sakurai, T.; Someya, T. Organic Nonvolatile Memory Transistors for Flexible Sensor Arrays. Science (80-. ). 2009, 5959, 1516-1519.

(8) Roberts, M. E.; Sokolov, A. N.; Bao, Z. Material and Device Considerations for Organic Thin-Film Transistor Sensors. J. Mater. Chem. 2009, 21, 3351-3363.

(9) Sokolov, A. N.; Roberts, M. E.; Johnson, O. B.; Cao, Y.; Bao, Z. Induced Sensitivity and Selectivity in Thin-Film Transistor Sensors via Calixarene Layers. Adv. Mater. 2010, 21, 2349-2353.

(10) Someya, T.; Sekitani, T.; Iba, S.; Kato, Y.; Kawaguchi, H.; Sakurai, T. A LargeArea, Flexible Pressure Sensor Matrix with Organic Field-Effect Transistors for Artificial Skin Applications. Proc. Natl. Acad. Sci. U. S. A. 2004, 27, 9966-9970.

(11) Wang, Z.; Safdar, M.; Jiang, C.; He, J. High-Performance UV-Visible-NIR Broad Spectral Photodetectors Based on One-Dimensional In2Te3 Nanostructures. Nano Lett. 2012, 9, 4715-4721.

(12) Wen, Y.; Yin, L.; He, P.; Wang, Z.; Zhang, X.; Wang, Q.; Shifa, T. A.; Xu, K.; Wang, F.; Zhan, X. Integrated High-Performance Infrared Phototransistor Arrays Composed of Nonlayered PbS-MoS2 Heterostructures with Edge Contacts. Nano Lett. 2016, 10, 6437-6444.

(13) Wang, J.; Liu, F.; Wang, G.; Wang, L.; Jiang, C. Novel Organic-Perovskite Hybrid Structure Forward Photo Field Effect Transistor. Org. Electron. 2016, $158-163$. 
(14) Wei, L.; Yao, J.; Fu, H. Solvent-Assisted Self-Assembly of Fullerene into Single-Crystal Ultrathin Microribbons as Highly Sensitive UV-visible Photodetectors. ACS Nano 2013, 9, 7573-7582.

(15) Jie, J. S.; Zhang, W. J.; Jiang, Y.; Meng, X. M.; Li, Y. Q.; Lee, S. T. Photoconductive Characteristics of Single-Crystal CdS Nanoribbons. Nano Lett. 2006, 9, 1887-1892.

(16) Fan, Z.; Ho, J. C.; Jacobson, Z. A.; Razavi, H.; Javey, A. Large-Scale, Heterogeneous Integration of Nanowire Arrays for Image Sensor Circuitry. Proc. Natl. Acad. Sci. 2008, 32, 11066-11070.

(17) Wang, J.; Gudiksen, M. S.; Duan, X.; Cui, Y.; Lieber, C. M. Highly Polarized Photoluminescence and Photodetection from Single Indium Phosphide Nanowires. Science (80-. ). 2001, 5534, 1455-1457.

(18) Kind, H.; Yan, H.; Messer, B.; Law, M.; Yang, P. Nanowire Ultraviolet Photodetectors and Optical Switches. Adv. Mater. 2002, 2, 158.

(19) Soci, C.; Zhang, A.; Xiang, B.; Dayeh, S. A.; Aplin, D. P. R.; Park, J.; Bao, X. Y.; Lo, Y.-H.; Wang, D. ZnO Nanowire UV Photodetectors with High Internal Gain. Nano Lett. 2007, 4, 1003-1009.

(20) Wang, J.-J.; Cao, F.-F.; Jiang, L.; Guo, Y.-G.; Hu, W.-P.; Wan, L.-J. High Performance Photodetectors of Individual InSe Single Crystalline Nanowire. $J$. Am. Chem. Soc. 2009, 43, 15602-15603. 
(21) Podzorov, V.; Menard, E.; Borissov, A.; Kiryukhin, V.; Rogers, J. A.; Gershenson, M. E. Intrinsic Charge Transport on the Surface of Organic Semiconductors. Phys. Rev. Lett. 2004, 8, 86602.

(22) Zhao, X.; Liu, T.; Zhang, Y.; Wang, S.; Li, X.; Xiao, Y.; Hou, X.; Liu, Z.; Shi, W.; Dennis, T. J. S. Organic Single-Crystalline Donor-Acceptor Heterojunctions with Ambipolar Band-Like Charge Transport for Photovoltaics. Adv. Mater. Interfaces 2018.

(23) Li, H.; Tee, B. C. K.; Cha, J. J.; Cui, Y.; Chung, J. W.; Lee, S. Y.; Bao, Z. HighMobility Field-Effect Transistors from Large-Area Solution-Grown Aligned C60 Single Crystals. J. Am. Chem. Soc. 2012, 5, 2760-2765.

(24) ZHAO, X.; Liu, T.; Cui, Y.; HOU, X.; Liu, Z.; Dai, X.; Kong, J.; SHI, W.; Dennis, T. J. S. Antisolvent-Assisted Controllable Growth of Fullerene Single Crystal Microwires for Organic Field Effect Transistors and Photodetectors. Nanoscale 2018.

(25) Shinohara, H. Endohedral Metallofullerenes. Reports Prog. Phys. 2000, 6, 843.

(26) Popov, A. A.; Yang, S.; Dunsch, L. Endohedral Fullerenes. Chem. Rev 2013, 8, 5989-6113.

(27) Kanbara, T.; Shibata, K.; Fujiki, S.; Kubozono, Y.; Kashino, S.; Urisu, T.; Sakai, M.; Fujiwara, A.; Kumashiro, R.; Tanigaki, K. N-Channel Field Effect Transistors with Fullerene Thin Films and Their Application to a Logic Gate Circuit. Chem. Phys. Lett. 2003, 3, 223-229. 
(28) Kobayashi, S.; Mori, S.; Iida, S.; Ando, H.; Takenobu, T.; Taguchi, Y.; Fujiwara, A.; Taninaka, A.; Shinohara, H.; Iwasa, Y. Conductivity and Field Effect Transistor of La2@C80 Metallofullerene.J.Am.Chem. Soc. 2003, 27, 81168117.

(29) Goedde, B.; Waiblinger, M.; Jakes, P.; Weiden, N.; Dinse, K.-P.; Weidinger, A. Nitrogen doped'C 60 Dimers (N@ C 60-C 60). Chem. Phys. Lett. 2001, 1, 1217.

(30) Mauser, H.; Hirsch, A.; Van Eikema Hommes, N. J. R.; Clark, T.; Pietzak, B.; Weidinger, A.; Dunsch, L. Stabilisierung von Atomarem Stickstoff Im Innenraum von C60. Angew. Chemie 1997, 24, 2858-2861.

(31) Bailey, S. W. D.; Lambert, C. J. The Electronic Transport Properties of N@ C60@(n, M) Carbon Nanotube Peapods. Phys. E Low-dimensional Syst. Nanostructures 2007, 1, 99-102.

(32) DONG, Q.; TIAN, W.-Q.; LI, W.-Q.; SUN, X.-D.; SUN, C.-C. Effects of Electric Field on the Structures and Electronic Properties of N@ C_(60), P@ C_(60) and As@C_(60)[J].Chem.J. Chinese Univ. 2010, 26.

(33) Kanai, M.; Porfyrakis, K.; Briggs, G. A. D.; Dennis, T. J. S. Purification by HPLC and the UV/Vis Absorption Spectra of the Nitrogen-Containing IncarFullerenes I NC 60, and I NC 70. Chem. Commun. 2004, No. 2, 210-211.

(34) Li, H.; Fan, C.; Vosgueritchian, M.; Tee, B. C.-K.; Chen, H. Solution-Grown Aligned C 60 Single-Crystals for Field-Effect Transistors. J. Mater. Chem. C 2014, 18, 3617-3624. 
(35) Mannsfeld, S. C. B.; Briseno, A. L.; Liu, S.; Reese, C.; Roberts, M. E.; Bao, Z. Selective Nucleation of Organic Single Crystals from Vapor Phase on Nanoscopically Rough Surfaces. Adv. Funct. Mater. 2007, 17, 3545-3553.

(36) Liu, S.; Briseno, A. L.; Mannsfeld, S. C. B.; You, W.; Locklin, J.; Lee, H. W.; Xia, Y.; Bao, Z. Selective Crystallization of Organic Semiconductors on Patterned Templates of Carbon Nanotubes. Adv. Funct. Mater. 2007, 15, 28912896.

(37) Ito, Y.; Virkar, A. A.; Mannsfeld, S.; Oh, J. H.; Toney, M.; Locklin, J.; Bao, Z. Crystalline Ultrasmooth Self-Assembled Monolayers of Alkylsilanes for Organic Field-Effect Transistors. J. Am. Chem. Soc. 2009, 26, 9396-9404.

(38) Bao, Z.; Locklin, J. Organic Field-Effect Transistors; CRC press, 2007.

(39) Tang, M. L.; Okamoto, T.; Bao, Z. High-Performance Organic Semiconductors: Asymmetric Linear Acenes Containing Sulphur. J. Am. Chem. Soc. 2006, 50, $16002-16003$.

(40) Ong, B. S.; Wu, Y.; Liu, P.; Gardner, S. High-Performance Semiconducting Polythiophenes for Organic Thin-Film Transistors. J. Am. Chem. Soc. 2004, 11, $3378-3379$.

(41) Wang, L.; Liu, B.; Yu, S.; Yao, M.; Liu, D.; Hou, Y.; Cui, T.; Zou, G.; Sundqvist, B.; You, H.; et al. Highly Enhanced Luminescence from Single-Crystalline C $60 \cdot 1$ M -Xylene Nanorods. Chem. Mater. 2006, 17, 4190-4194.

(42) H. H. Choi, K. Cho, C. D. F. et al. Critical Assessment of Charge Carrier Mobility Extraction. Nat. Mater. 2017, 1, 2-7. 
(43) Podzorov, V.; Menard, E.; Rogers, J. A.; Gershenson, M. E. Hall Effect in the Accumulation Layers on the Surface of Organic Semiconductors. Phys. Rev. Lett. 2005, 22, 226601.

(44) Sakanoue, T.; Sirringhaus, H. Band-like Temperature Dependence of Mobility in a Solution-Processed Organic Semiconductor. Nat. Mater. 2010, 9, 736-740.

(45) Liu, C.; Minari, T.; Lu, X.; Kumatani, A.; Takimiya, K.; Tsukagoshi, K. Solution-Processable Organic Single Crystals with Bandlike Transport in FieldEffect Transistors. Adv. Mater. 2011, 4, 523-526.

(46) Kim, B. J.; Yu, H.; Oh, J. H.; Kang, M. S.; Cho, J. H. Electrical Transport through Single Nanowires of Dialkyl Perylene Diimide. J. Phys. Chem. C 2013, 20, 10743-10749.

(47) Xu, X.; Yao, Y.; Shan, B.; Gu, X.; Liu, D.; Liu, J.; Xu, J.; Zhao, N.; Hu, W.; Miao, Q. Electron Mobility Exceeding $10 \mathrm{~cm} 2 \mathrm{~V}-1 \mathrm{~S}-1$ and Band-Like Charge Transport in Solution-Processed n-Channel Organic Thin-Film Transistors. Adv. Mater. 2016, 26, 5276-5283.

(48) Minder, N. A.; Ono, S.; Chen, Z.; Facchetti, A.; Morpurgo, A. F. Band-Like Electron Transport in Organic Transistors and Implication of the Molecular Structure for Performance Optimization. Adv. Mater. 2012, 4, 503-508.

(49) Wang, Q.; Wen, Y.; He, P.; Yin, L.; Wang, Z.; Wang, F.; Xu, K.; Huang, Y.; Wang, F.; Jiang, C. High-Performance Phototransistor of Epitaxial PbS Nanoplate-Graphene Heterostructure with Edge Contact. Adv. Mater. 2016, 30, 6497-6503. 
(50) Noh, Y.-Y.; Kim, D.-Y.; Yoshida, Y.; Yase, K.; Jung, B.-J.; Lim, E.; Shim, H.K. High-Photosensitivity P-Channel Organic Phototransistors Based on a Biphenyl End-Capped Fused Bithiophene Oligomer. Appl. Phys. Lett. 2005, 4, 43501.

(51) Noh, Y.-Y.; Kim, D.-Y.; Yase, K. Highly Sensitive Thin-Film Organic Phototransistors: Effect of Wavelength of Light Source on Device Performance. J. Appl. Phys. 2005, 7, 74505.

(52) Saragi, T. P. I.; Londenberg, J.; Salbeck, J. Photovoltaic and Photoconductivity Effect in Thin-Film Phototransistors Based on a Heterocyclic Spiro-Type Molecule. AIP 2007.

(53) O’Brien, G. A.; Quinn, A. J.; Tanner, D. A.; Redmond, G. A Single Polymer Nanowire Photodetector. Adv. Mater. 2006, 18, 2379-2383.

(54) Zhang, Y.; Liu, T.; Meng, B.; Li, X.; Liang, G.; Hu, X.; Wang, Q. J. Broadband High Photoresponse from Pure Monolayer Graphene Photodetector. Nat. Commun. 2013, 1811.

(55) Xue, G.; Fan, C.; Wu, J.; Liu, S.; Liu, Y.; Chen, H.; Xin, H. L.; Li, H. Ambipolar Charge Transport of TIPS-Pentacene Single-Crystals Grown from Non-Polar Solvents. Mater. Horiz. 2015, 3, 344-349.

(56) Ahmed, R.; Kadashchuk, A.; Simbrunner, C.; Schwabegger, G.; Havlicek, M.; G??owacki, E.; Sariciftci, N. S.; Baig, M. A.; Sitter, H. Photosensitivity of Top Gate C60 Based OFETs: Potential Applications for High Efficiency Organic Photodetector. Org. Electron. physics, Mater. Appl. 2014, 1, 175-181. 

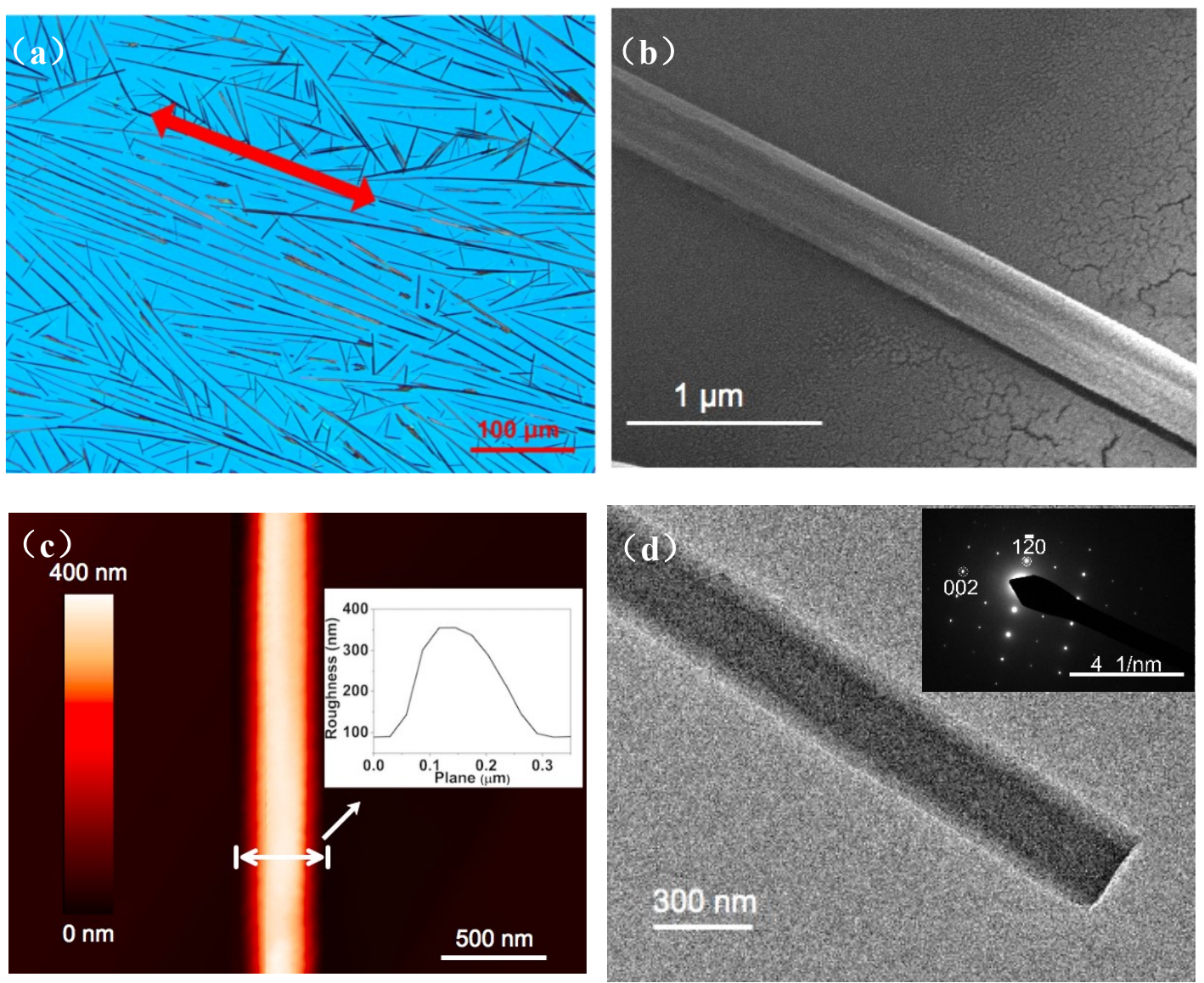

Figure 1 (a) OM and (b) SEM images of self-aligned N@C $\mathrm{C}_{60}$ needle crystals; (c) AFM image of a needle crystal showing facted shape; (inset) selected area roughness analysis; (d) TEM image of a needle crystal; (inset) SAED pattern containing a single set of spots, indicating the crystallinity of needle. 
(a)

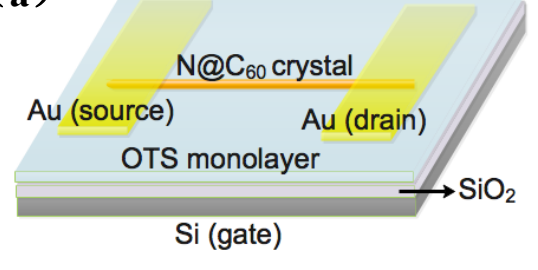

(c)

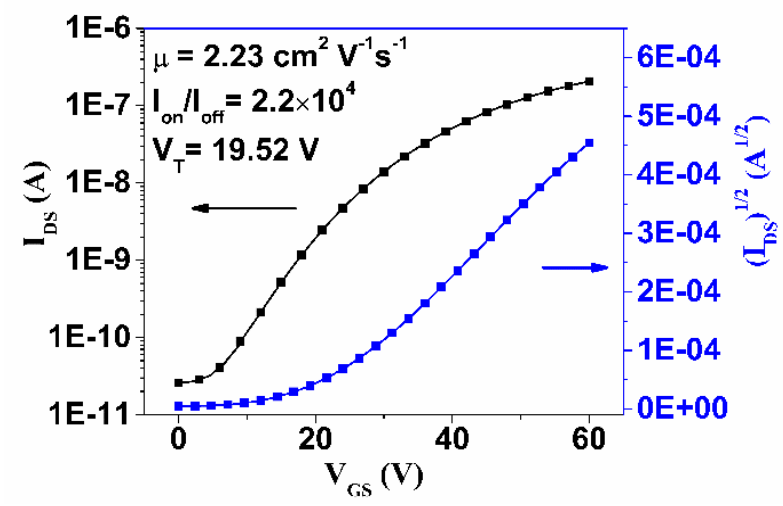

(b)

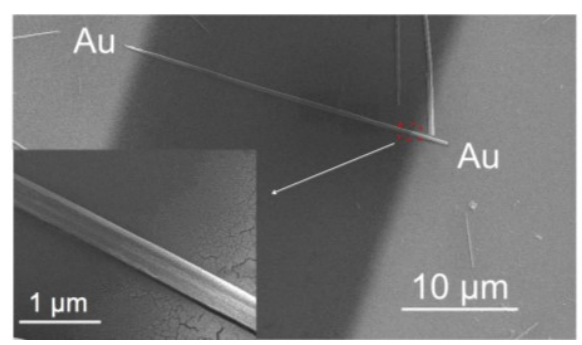

(d)

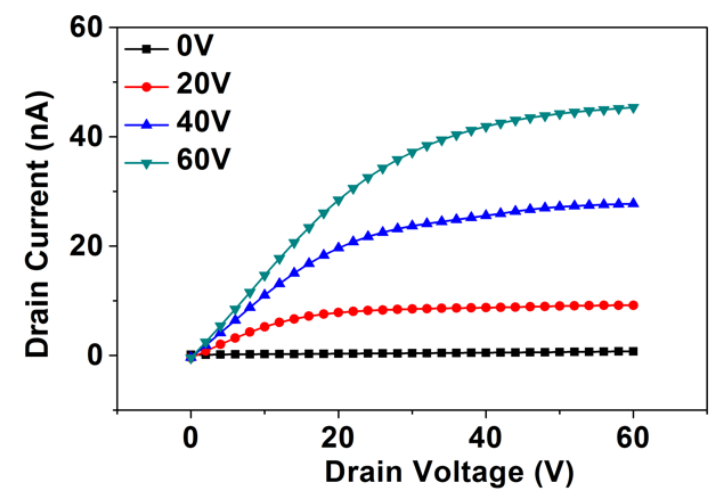

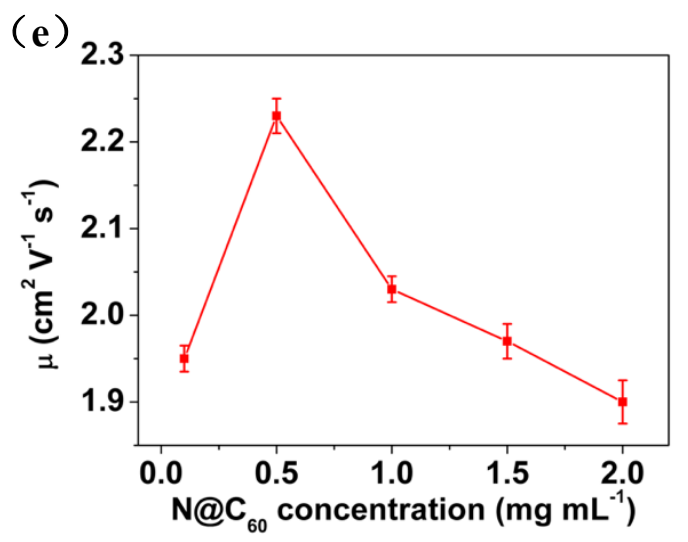

Figure 2 (a) Schematic of a typical device; (b) SEM image showing N@C60 needle crystal between source (S) and drain (D) electrodes, channel length (L) was measured from the real channel length and channel width (W) was measured from the contacting area of the crystals that cross the S and D electrodes; (c) and (d) Typical transfer and output characteristics of the FETs based on $\mathrm{N} @ \mathrm{C}_{60}$ needle crystals grown from a solution with a concentration of $0.5 \mathrm{mg} \mathrm{mL}^{-1}$; (e) OFET mobilities as a function of the $\mathrm{N} @ \mathrm{C}_{60}$ concentrations for crystallization. 
(a)

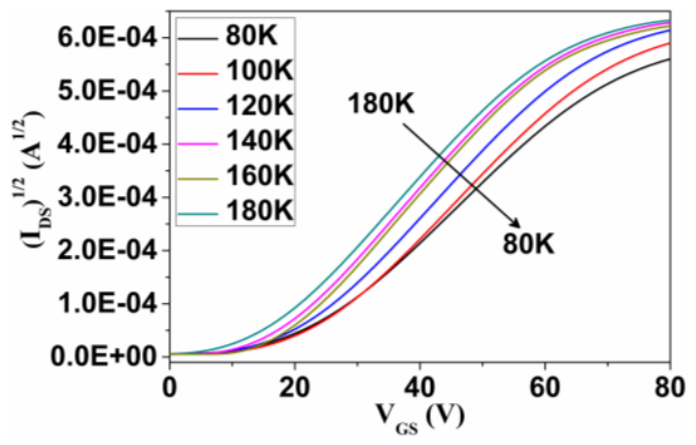

(c)

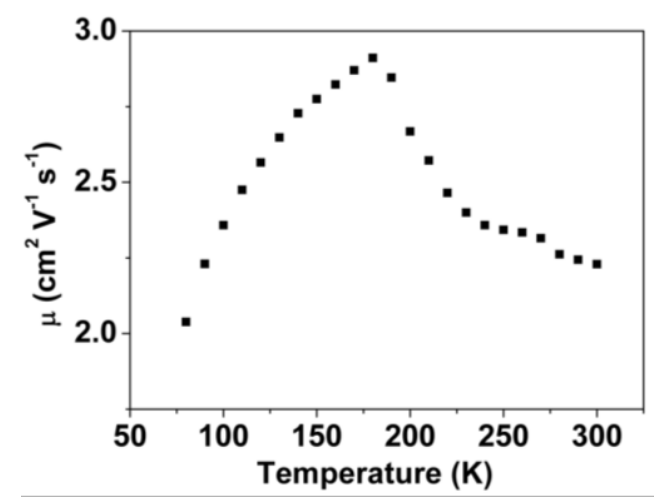

(b)

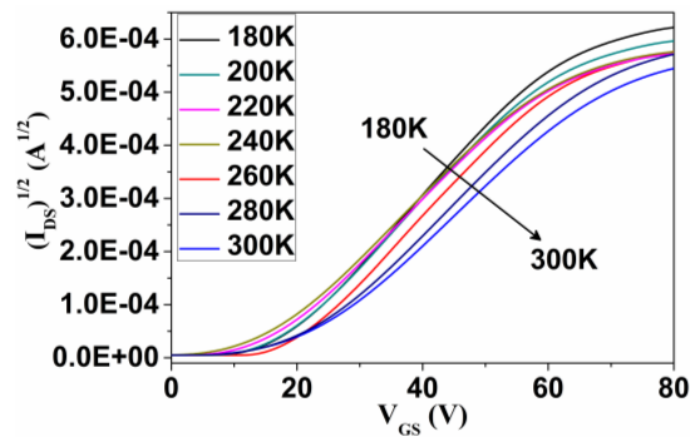

(d)

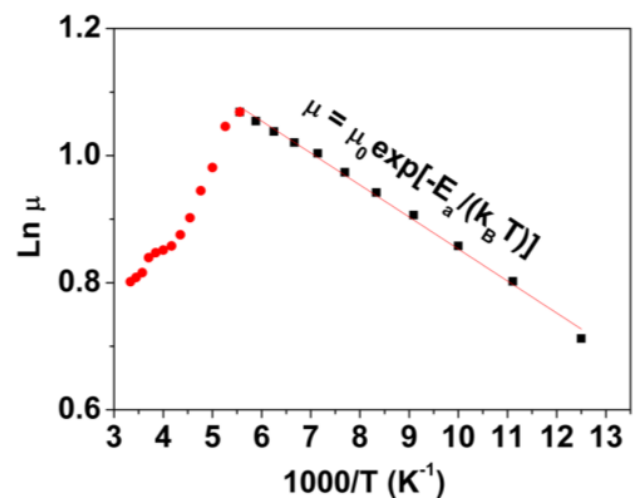

Figure 3 Square root of drain current $\left(\mathrm{I}_{\mathrm{DS}}\right)^{1 / 2}$ versus gate voltage $\left(\mathrm{V}_{\mathrm{GS}}\right)$ for the $\mathrm{N} @ \mathrm{C}_{60}$ needle crystal OFETs with a drain voltage of $80 \mathrm{~V}$ as measured at the temperature from (a) 80 to $180 \mathrm{~K}$ and (b) 180 to $300 \mathrm{~K}$; (c) temperature dependence of field effect mobility ( $\mu$ ) for $\mathrm{N} @ \mathrm{C}_{60}$ single crystal OFETs; (d) $\ln (\mu)$ versus 1/T for $\mathrm{N} @ \mathrm{C}_{60}$ single crystal OFETs. 


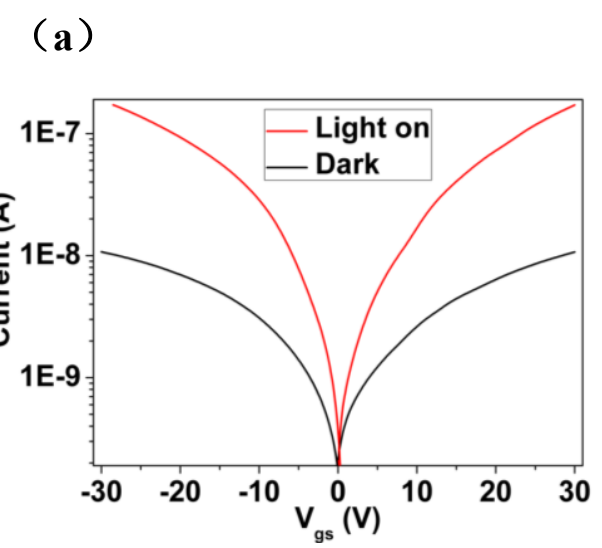

(c)

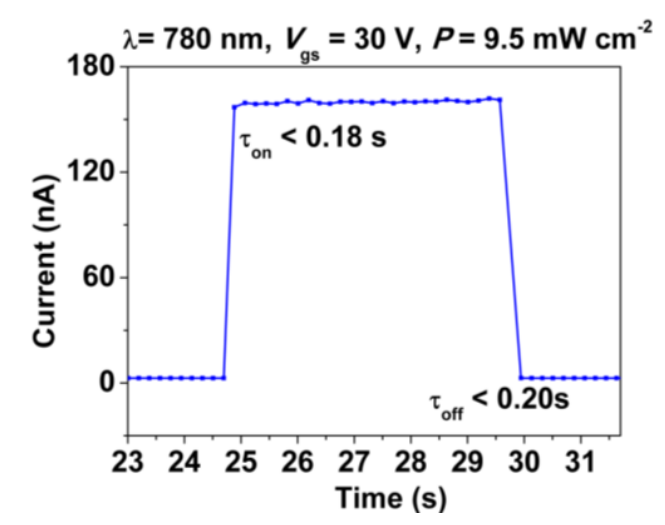

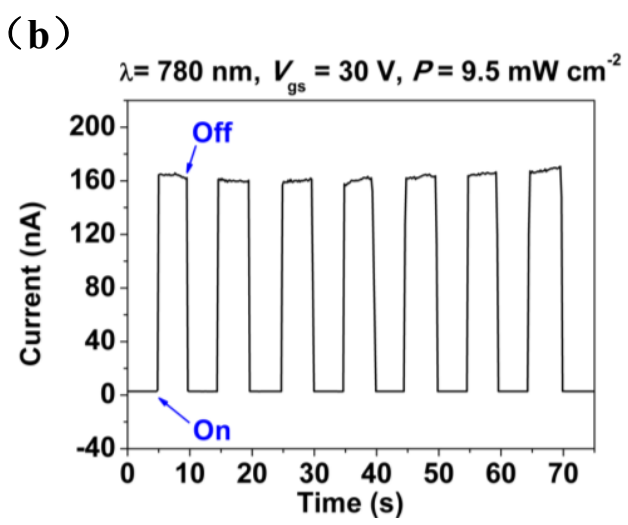

(d)

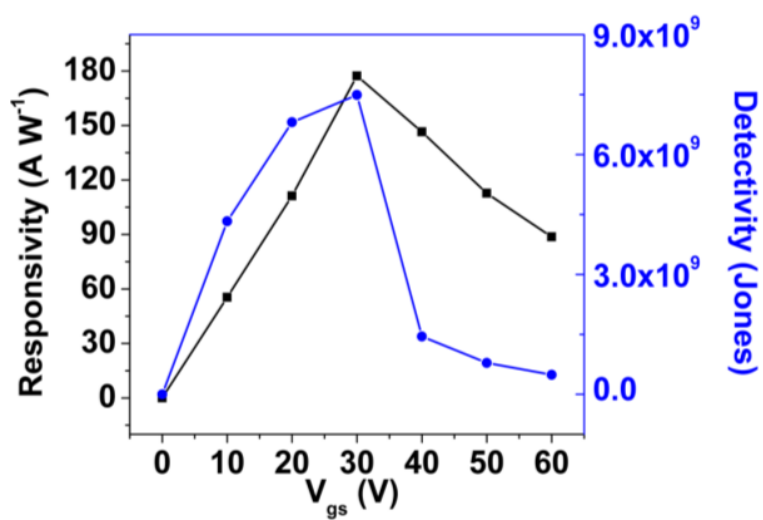

Figure 4 Gate-voltage-tunable responsivity and detectivity of $\mathrm{N} @ \mathrm{C}_{60}$ single crystal photodetectors. (a) I-V characteristics of the $\mathrm{N} @ \mathrm{C}_{60}$ needle crystals with and without NIR irradiation at a light density of $9.5 \mathrm{~mW} \mathrm{~cm}^{-2}$; (b) Time-resolved photoresponse was measured at $780 \mathrm{~nm}$, which indicates a highly stable and reversible response of the phototransistor; (c) Temporal response exhibits fast photoswitching $\left(\tau_{\mathrm{on}}<0.18 \mathrm{~s}, \tau_{\mathrm{off}}<\right.$ $0.20 \mathrm{~s}$ ); (d) Gate-tunable behavior for responsivity and detectivity with $P=9.5 \mathrm{~mW} \mathrm{~cm}^{-}$ 2. 
Table 1 Comparison of performance for photodetectors based on various organic semiconductors

\begin{tabular}{|c|c|c|c|c|}
\hline Material & $\begin{array}{c}\text { Wavelength } \\
(\mathrm{nm})\end{array}$ & $\begin{array}{l}\text { Power density } \\
\left.\qquad(\mathrm{mW} \mathrm{cm})^{-2}\right)\end{array}$ & $\begin{array}{l}\text { Responsivity } \\
\qquad\left(\mathrm{A} \mathrm{W}^{-1}\right)\end{array}$ & Reference \\
\hline BPTT & 380 & 1.55 & 82 & 50 \\
\hline \multirow{2}{*}{ pentacene } & 365 & 5.0 & 50 & \\
\hline & 650 & 5.0 & 0.45 & $J_{1}$ \\
\hline Spiro-4p-CPDT & 370 & & 25 & 52 \\
\hline С8BТВТ & 473 & 2.7 & 33 & 13 \\
\hline $\mathrm{C}_{60}$ & 780 & 1.5 & 82.6 & 24 \\
\hline $\mathrm{C}_{60}$ & 470 & 0.000523 & 1047 & 56 \\
\hline \multirow[b]{2}{*}{$\mathrm{C}_{60}$} & 360 & 4.38 & 75.3 & \\
\hline & 650 & 4.38 & 90.4 & 14 \\
\hline F8T2 & 405 & 3 & 0.0004 & 53 \\
\hline graphene & 532 & & 8.61 & 54 \\
\hline $\mathrm{N} @ \mathrm{C}_{60}$ & 780 & 9.5 & 177.3 & In this work \\
\hline
\end{tabular}


Table of Contents Graphic

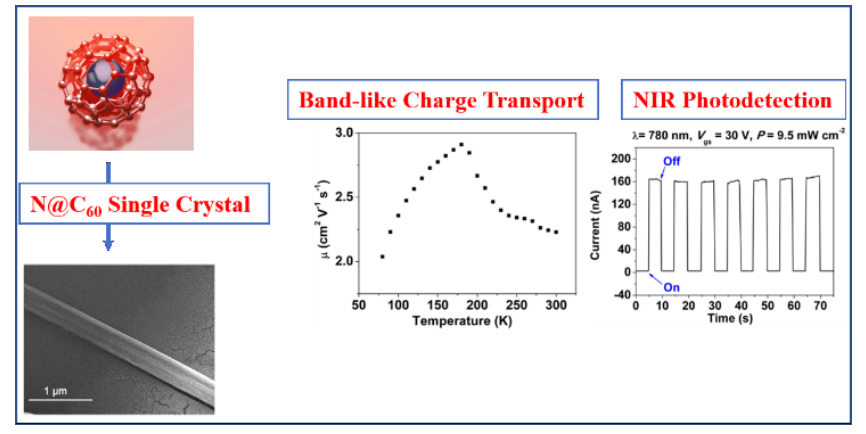

